\title{
BMJ Open Assessing the effects of changes in care commissioning guidelines at a tertiary centre in London on the provision of NHS-funded procedures of limited clinical effectiveness: an 11-year retrospective database analysis
}

Shafiq Rahman, ${ }^{1}$ Benjamin Langridge,${ }^{2}$ Nadine Hachach-Haram, ${ }^{3}$ Esther Hansen, ${ }^{3}$ Anna Bootle, ${ }^{3}$ Nicola Bystrzonowski, ${ }^{3}$ Stephen Hamilton, ${ }^{3}$ Afshin Mosahebi ${ }^{1,3}$

To cite: Rahman S, Langridge B, Hachach-Haram N, et al. Assessing the effects of changes in care commissioning guidelines at a tertiary centre in London on the provision of NHS-funded procedures of limited clinical effectiveness: an 11-year retrospective database analysis. BMJ Open 2017;7:e015324. doi:10.1136/ bmjopen-2016-015324

- Prepublication history for this paper is available online. To view these files please visit the journal online (http://dx.doi.org/10.1136/ (bmjopen-2016-015324).

Received 28 November 2016 Revised 18 April 2017 Accepted 8 May 2017

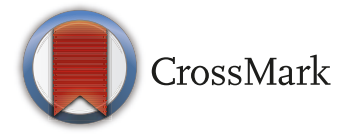

${ }^{1}$ Division of Surgery and Interventional Science, University College London, London, England

${ }^{2}$ Division of Medicine, University College London, London, England

${ }^{3}$ Department of Plastic Surgery, Royal Free Hospital, London, England

Correspondence to Shafiq Rahman; shafiq.rahman@nhs.net

\section{ABSTRACT}

Objectives The main objective of this study was to assess the impact of changes in care commissioning policies on National Health Service (NHS)-funded cosmetic procedures over an 11-year period at our centre.

Setting The setting was a tertiary care hospital in London regulated by the North Central London Hospitals NHS Trust care commissioning group.

Participants We included all patients logged on to our database at the time of the study which was 2087 but later excluded 61 from analysis due to insufficient information.

Primary and secondary outcome measures The main outcome measures were the results of tribunal assessment for different cosmetic surgeries which were either accepted, rejected or inconclusive based on the panel meeting.

Results There were a total of 2087 patient requests considered between 2004 and 2015, of which 715 (34\%) were accepted, 1311 (63\%) were declined and 61 (3\%) had inconclusive results. The implementation of local care commissioning guidelines has reduced access to cosmetic surgeries. Within this period, the proportion of procedures accepted has fallen from $36 \%$ in 2004 to $21 \%$ in 2015 ( $\chi^{2}$; $\mathrm{p}<0.05,95 \% \mathrm{Cl})$.

Conclusion Local guidance on procedures of limited clinical effectiveness is a useful, although not evidencebased selection process to reduce access to cosmetic surgery in line with increasing financial constraints. However, patients with a physical impairment may not receive treatment in comparison to previous years, and this can have a negative impact on their quality of life.

\section{INTRODUCTION}

Attitudes toward beauty are culture bound and have varied across our history, with modern media heavily shaping the emphasis on a particular image. Inherently, there is an increasing pressure on people to correct aberrations of their appearance, which, in the

\section{Strengths and limitations of this study}

- Large patient cohort assessed over an 11-year period.

- First study of its nature observing a trend in procedures of limited clinical effectiveness due to guideline changes at a single centre.

- The main limitations were that there was some inconclusive results that could not be traced as well as the study being retrospective in design.

UK, has been observed by greater demand for aesthetic surgeries. ${ }^{1}$ Cosmetic procedures can additionally have psychological and functional benefits. ${ }^{2}{ }^{3}$ The implications of growing financial pressures, however, on the National Health Service (NHS) have led to care commissioning groups restricting access ${ }^{45}$ through the introduction of local guidelines. ${ }^{46}$ This has also been influenced by national guidelines issued through BAPRAS $^{7}$ which emphasise the need for functional symptoms. However, their application has often been arbitrary, and clinicians have criticised them for being impractical and not evidence based. ${ }^{6}$

In this study, we review the effects of changes to local guidelines on selection practices for NHS-funded cosmetic procedures. In our centre, any procedure of limited clinical effectiveness (POLCE) request is discussed at a multidisciplinary exceptional treatment panel. The panel uses a homogeneous assessment criteria with information from surgical assessments, clinical photography, psychological assessment and standardised psychometric questionnaires to consider the suitability of surgery on both aesthetic and 


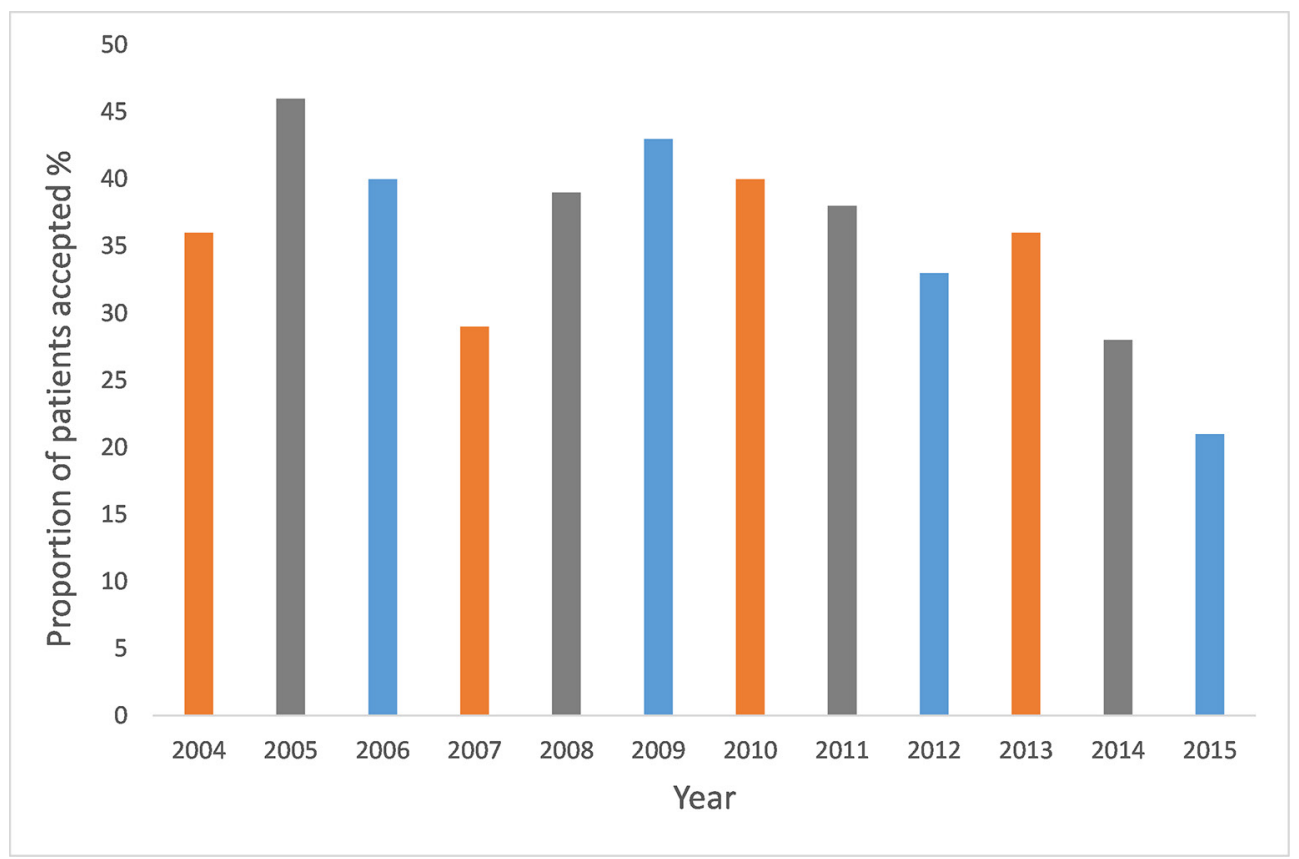

Figure 1 Proportion of tribunal cases accepted for surgery annually between 2004 and 2015.

psychosocial grounds, alongside risks. All of the applicants are reviewed by this criteria prior to selection. Psychological assessment is vital to filter out patients who should access psychological treatment as opposed to surgery, which in these cases would be associated with undesirable outcomes. ${ }^{8}$ Our assessment was based on the guidelines issued by the North Central London care commissioning group. They have issued general criteria including being a non-smoker, having a minimum age of 18 , having a significant impairment of activities of daily living as well as not suffering from depression, anxiety, obsessive compulsive disorder or body dysmorphic disorder. There has also been procedure-specific guidelines set out for each different clinical condition. Our panel collated information through both psychological and physical assessments in view of the general as well as procedure-specific criteria set out by the care commissioning guidelines (CCG). The selection panel was set up locally and consisted of a plastic surgeon, a clinical psychologist, an operative manager and a general surgeon.

The objective of this retrospective analysis was to analyse a large patient cohort in a single centre over a significant time period. It allowed for assessment of the impact of changes in POLCE guidance on the provision of cosmetic surgeries within the NHS.

\section{METHODOLOGY}

Data collection was retrospective involving analysis of a database that recorded POLCE requests between 2004 and 2015 at a tertiary care centre. This computerised data $\log$ was maintained by the tribunal review panel which assessed individual cases. In order to maintain consistency and limit bias, variation in membership of the panel was kept to a minimum. Over the 11-year period, the clinical psychologist changed once, and the plastic surgeon changed only three times. The membership of the operative manager changed once and that of the general surgeon just four times over 11 years. Although the central computerised record had biodata of patients, we de-identified their personal details when conducting data collection for the study. Retrieval of information from the database was performed between January 2016 and March 2016 and included the date of the tribunal meeting, the surgery requested as well as the outcome of the meeting (ie, provisionally accepted, accepted, declined or inconclusive). Patients who were provisionally accepted were further searched on a separate system which allowed access to operative records, thus enabling us to identify whether they were successful in obtaining surgery from their initial status of having been provisionally accepted. The final amalgamated data consisted of those who had surgery, those who were rejected for surgery and cases which were inconclusive. We included all patients who were logged on to our database (2087 cases). This aided to eliminate bias and obtain a fair representation, but we later had to exclude those from analysis who had insufficient details on our system and whose outcomes could not be traced. This was the inconclusive group.

The study was approved by the clinical governance unit. It did not necessitate permission from an ethical committee, since human subjects were not directly involved and the nature of the work was a retrospective assessment of outcome data only. All statistical analysis was performed with SPSS version 24, and the Pearson $\chi^{2}$ as well as the Fisher's exact test was used to assess differences in the proportion of surgeries accepted at a 95\% CI. 
Table 1 Percentage of breast augmentations accepted annually between 2004 and 2015

\begin{tabular}{lcccccccccccc} 
Year & $\mathbf{2 0 0 4}$ & $\mathbf{2 0 0 5}$ & $\mathbf{2 0 0 6}$ & $\mathbf{2 0 0 7}$ & $\mathbf{2 0 0 8}$ & $\mathbf{2 0 0 9}$ & $\mathbf{2 0 1 0}$ & $\mathbf{2 0 1 1}$ & $\mathbf{2 0 1 2}$ & $\mathbf{2 0 1 3}$ & $\mathbf{2 0 1 4}$ & $\mathbf{2 0 1 5}$ \\
\hline Accepted & 0 & 27 & 17 & 23 & 19 & 12 & 15 & 50 & 20 & 31 & 50 & 18 \\
Rejected & 100 & 73 & 83 & 77 & 81 & 88 & 85 & 47 & 80 & 38 & 37 & 82 \\
Inconclusive (\%) & & & & & & & & 3 & & 31 & 13 \\
\hline
\end{tabular}

\section{RESULTS}

There were a total of 2087 cases between the years 2004 and 2015, of which $715(34 \%)$ were accepted, $1311(63 \%)$ were declined and 61 (3\%) had inconclusive results. The proportion of tribunal cases accepted per year is demonstrated in figure 1.

Overall, there was a decrease in the proportion of cosmetic procedures accepted from $36 \%$ in 2004 to $21 \%$ in $2015\left(\chi^{2} ; \mathrm{p}<0.05,95 \% \mathrm{CI}\right)$. There were a total of 225 tribunals concerning breast augmentation of which 158 $(70 \%)$ were declined, $59(26 \%)$ were accepted and 8 (4\%) were inconclusive. The percentage proportion of breast augmentations accepted and rejected annually is demonstrated in table 1 .

Subgroup analysis demonstrated a lower rate of acceptance for bilateral breast augmentation (12\% accepted) in comparison to applications for unilateral breast augmentation ( $66 \%$ accepted). A $\chi^{2}$ assessment proved this to be significant $(\mathrm{p}<0.05,95 \% \mathrm{CI})$.

In total, there were 565 tribunals concerning abdominoplasties; of these, 325 were declined, 217 were accepted and 23 had inconclusive results. The annual percentages of those rejected and approved at tribunals are given in table 2 .

There were 249 tribunal cases regarding breast reduction surgeries overall; of these, 132 (53\%) were rejected, $111(45 \%)$ were accepted and the remainder had inconclusive results. The following 3 years had the highest proportion of breast reduction surgeries rejected: 2015 (80\% declined), 2014 (60\% declined) and $2013(50 \%$ declined). Fisher analysis between 2013 and 2015 showed a statistically significant increase in the rejection rate $(\mathrm{p}<0.05,95 \%$ CI $)$.

The majority of mastopexies were declined, totalling to 107 cases overall. Across the sampling period, 20 were approved. Six liposuctions were approved between 2004 and 2015.

There was a $36 \%$ acceptance rate for breast augmentation surgery between January and July of 2015 which decreased to $25 \%$ from August to December of 2015. The acceptance rate for breast reduction surgeries decreased from $55 \%$ to $18 \%$ in the same time period which was statistically significant (Fisher's exact test; $\mathrm{p}<0.05,95 \%$ CI).

There have been a number of inconclusive results in our study, and they represent patients which were lost to follow-up or whose records could not be traced. For this reason, they were not considered as part of the main data set as their outcomes were unknown.

Our results have also included a large variety of other surgery types ranging from rhinoplasty, otoplasty, body contouring and mastectomies which have constituted the remainder of the tribunal figures. Their discussion, however, would be beyond the scope of this article, and we have primarily focused on those surgeries which have been more common as well as having been affected by guideline changes at our centre.

\section{DISCUSSION}

The implementation of local CCG guidelines has restricted access to cosmetic surgeries. Overall, it has significantly reduced the proportion of procedures accepted at tribunals from $36 \%$ in 2004 to $21 \%$ in 2015 $\left(\chi^{2} ; \mathrm{p}<0.05,95 \% \mathrm{CI}\right)$. In 2011, the acceptance rate was $38 \%$; this figure fell after the implementation of the 2012 guidelines to $33 \%$ and continued to fall after the introduction of new guidelines in 2013 to $21 \%$ by the year 2015. Overall, there has been an increase in the proportion of procedures rejected from $64 \%$ in 2004 to $71 \%$ in 2015. The trends observed suggest stricter regulation by care commissioning groups over time with less surgeries accepted and more declined. Our results have been measured against a number of guidelines issued by the North Central London care commissioning group. These have been subject to numerous changes over time and are amalgamated in figure 2. Three sets of modifications were introduced to policies in the years 2012, 2013 and 2015 .

\section{Effects of changing policies}

Guidelines issued by the North Central London CCG have changed. Prior to 2012, breast augmentation surgery was accepted as long as there was a minimum of

\begin{tabular}{|c|c|c|c|c|c|c|c|c|c|c|c|c|}
\hline Year & 2004 & 2005 & 2006 & 2007 & 2008 & 2009 & 2010 & 2011 & 2012 & 2013 & 2014 & 2015 \\
\hline Accepted & 80 & 36 & 52 & 26 & 49 & 30 & 40 & 47 & 48 & 37 & 42 & 21 \\
\hline Inconclusive (\%) & & & & & & & 2 & & 2 & 1 & 8 & 5 \\
\hline
\end{tabular}




\begin{tabular}{|l|}
2012 \\
Greater than 2 cup size differences \\
for breast asymmetry. Pre 2012 a \\
difference of $20 \%$ was considered \\
significant
\end{tabular}

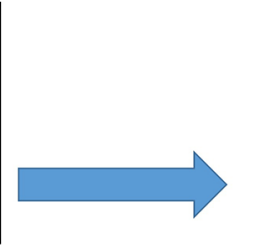

2013

Documented evidence of having a BMI between $18 \leq 27$ for a minimum of 2 years for abdominoplasties

\section{5}

Exclusion of bilateral breast augmentation with exceptions for cancer/burns or congenital amastia. Inclusion of patients for reduction mammoplasty to cup $\mathrm{H}$ or larger Increase of BMI criteria to $35 \mathrm{~kg} / \mathrm{m}^{2}$ for abdominoplasty in the case of post bariatric surgery

Figure 2 Changes in guidelines for the years 2012, 2013 and 2015 issued by the North Central London Hospitals NHS Trust care commissioning group. BMI, body mass index.

a $20 \%$ difference in breast sizes; however, this increased to a difference of more than two cup sizes by 2012. This has decreased the proportion of these surgeries accepted from $50 \%$ in 2011 to $18 \%$ by the year 2015 (Fisher's exact test; $\mathrm{p}<0.05)$. It is of interest to note that between 2004 to 2015, the likelihood of having an application for breast augmentation surgery accepted was greater for unilateral in comparison to bilateral cases $\left(\chi^{2} ; \mathrm{p}<0.05\right)$.

In 2013, the North Central London Care Commissioning group altered their selection criteria for abdominoplasties by setting the body mass index (BMI) standard at between 18 and $\leq 27$ with documented evidence for a minimum of 2 years. This reduced the proportion of abdominoplasties accepted from $37 \%$ in 2013 to $21 \%$ in 2015 (Fisher's exact test; $\mathrm{p}<0.05$ ) and reflects that the new guideline has decreased the ratio of successful applicants in getting abdominoplasties approved.

As of July 2015, new changes were implemented. These included exclusion of bilateral breast augmentation with exceptions being cancer/burns or congenital amastia. Reduction mammoplasty criteria was changed to having a breast size to cup $\mathrm{H}$ or larger. Abdominoplasty for postbariatric surgery patients who have lost at least $50 \%$ of original excess weight must have a BMI limit equal or less than $35 \mathrm{~kg} / \mathrm{m}^{2}$ which marks an increase to the previous limit of $27 \mathrm{~kg} / \mathrm{m}^{2}$. The short impact of these new guidelines was assessed over 6-month periods both before and after implementation. There was a $36 \%$ acceptance rate for breast augmentation surgeries between January and July of 2015 which decreased to $25 \%$ from August to December of 2015 after the new policy came into practise. The acceptance rate for breast reduction surgeries decreased from $55 \%$ to $18 \%$ (Fisher's exact test; $\mathrm{p}<0.05$ ) in the same time period after introduction of the new guidelines.

One of the main limitations of the study was the inconclusive set of results. This cohort of patients were either lost to follow-up or their records were insufficient on our central database. For this reason, they were not considered as part of the main data set as their outcomes were unknown and could not be traced. Their proportion, however, was low with regard to the data set overall and thus was assumed to have a minimal effect on the outcomes of the study overall.

\section{Health gains of cosmetic surgeries}

Cosmetic surgeries serve an aesthetic benefit, and more importantly, the functional advantages can have a significant effect in improving the quality of life. Coriddi et $a t^{\theta}$ have statistically demonstrated improvement in over 20 functional variables post abdominoplasty. This has included a reduction of neck pain, better posture, exercise tolerance, increased ability to mobilise and more. In addition, psychological benefits of abdominoplasty are equally important. Bolton $e a^{10}$ have used the appearance evaluation subscale of the Multidimensional Body-Self Relations Questionnaire to show improvement postsurgery in acceptance of body image. Other cosmetic procedures have also proven functional and psychological benefits with breast reduction demonstrating a decrease in compressive back forces. ${ }^{11}$ Klassen et $a l^{12}$ have used the SF-36 health questionnaire to show improved physical and social outcomes at 6 months post breast reduction in 166 women. Restricting access to these procedures can therefore negatively impact the quality of life in these patient cohorts.

\section{Compliance with guidelines}

Compliance with POLCE guidance has often been criticised for poor implementation and not being adhered to with clinical discretion having overridden policies at times. ${ }^{6}$ At our centre, there have been $20(16 \%)$ cases of mastopexies and $6(16 \%)$ cases of liposuctions approved when local CCG guidance states these procedures should not be funded. In looking at these 26 patients' medical notes, there have been important clinical and psychological grounds for these surgeries to be approved. In 
the case of liposuctions, the predominant indication has been lipodystrophy causing an unusual appearance (eg, large buffalo hump) associated with significant psychological distress for which patients have genuinely had difficulty in coping with. Similarly, for mastopexies, in addition to there being psychological indications for surgery, there has also been strong clinical grounds for approval. This has included skin eczema underneath the breasts following significant weight loss as well as severe or unusual involutional changes of the breasts with ptosis. It is therefore important to note that while guidelines should be complied to, there should be room for clinical decision making.

\section{National variation of guidelines}

There is significant variation in policies on how to manage POLCEs. This has been seen in the case of bilateral breast reduction (BBR) where 21 primary care trusts out of 245 have previously reported that they would not fund BBRs. ${ }^{13}$ Variation between local and national guidelines has also existed. ${ }^{4}$ Trusts offering BBR showed considerable discrepancy in terms of their selection criteria with 81 primary care trusts reporting that a minimum $500 \mathrm{~g}$ resection per breast is needed while five required more than $750 \mathrm{~g}$. Cup size criteria have also varied among trusts from $\mathrm{DD}$ to $\mathrm{F}$, and some have mandated the use of 3D body imaging to delineate breast volume. ${ }^{13}$ National guidelines concerning reduction mammoplasty published by BAPRAS $^{7}$ in 2014 have been clearly modified locally at different trusts in the UK. ${ }^{13}$ This is most likely due to the fact that policies from BAPRAS are clinically informed and evidence based, whereas those issued locally are driven by financial constraints. In a study by Henderson, ${ }^{14}$ it has been identified that gross variation exists in local guidelines across many different procedures when compared with national policies. This has applied to many surgeries including removal of implants, mastopexy, abdominoplasty, facelift, blepharoplasty, rhinoplasty, pinnaplasty, body lifting, surgery for gynaecomastia as well as tattoo removal. Only $62 \%$ of trusts within the UK have commissioned abdominoplasties. ${ }^{14}$ Again, significant variation in terms of policies has been exhibited with the BMI criteria ranging from 25 to $30 \mathrm{~kg} / \mathrm{m}^{2}$ across different trusts, while national guidelines set by the "Action on Plastic Surgery" (AOPS) document has set an upper BMI limit of $27 \mathrm{~kg} /$ $\mathrm{m}^{2} .{ }^{14}$ Only $9 \%$ of primary care trusts allow funding for mastopexy if there is significant ptosis of the nipple areolar complex. Similar discrepancies for other procedures have been noted, and this has produced the notion of a 'postcode lottery', ${ }^{15}$ where geographical differences influence whether a procedure can be approved.

It is fair to state that therefore certain patients who have a physical impairment may be deprived of surgical intervention based on their location as guidelines vary across the country. This can be overcome if a homogeneous set of policies are adapted nationally so that all patients are given an equal opportunity. This concept has been reiterated in the literature by Russell et al. ${ }^{16} \mathrm{~A}$ source of the problem may arise from funding differences because historically commissioning of resources is influenced by population size as well as socioeconomic status. Areas like London have been renowned to obtain a higher percentage budget than the national average. ${ }^{17}$ This problem can be perhaps overcome by a more even distribution of funding so that regional differences in policies are minimised. The British Medical Association has also emphasised that care commissioning groups should work more closely across different regions and adhere to national guidelines. ${ }^{18}$ Policies may also appeal to surgeons if there is room for clinical decision making and evidence-based recommendations, not just guidance on process.

One issue evident from this study is that the proportion of patients having their procedures approved over the last 11 years at the tribunal review panel has reduced significantly. This has been due to a number of guideline changes introduced by the North Central London care commissioning group which has restricted access to surgeries between 2004 and $2015\left(\chi^{2} ; \mathrm{p}<0.05\right)$. This therefore raises the question whether patients are unable to access treatment that may be of benefit to their quality of life. It would be helpful to know whether the trend observed in this study can be generalised to one nationally across the UK. This could identify whether treatment at individual centres is becoming increasingly difficult to access in addition to regional guideline variation. The authors would like to therefore encourage similar work to be conducted at other NHS hospital trusts to see if the results are mirrored, and this would strengthen the external validity of the data in the current work. Regardless, given the large patient cohort, this study offers a fair representation of a trend that potentially exists within the NHS. We may be observing a healthcare service which is denying patients genuine treatment for physical and psychological conditions that they have.

\section{CONCLUSION}

The changes in guidelines for cosmetic surgeries at this centre have overall reduced the number of procedures approved at the exceptional treatment panel meetings between 2004 and 2015. This is perhaps reflective of growing financial pressures on the NHS in which selection criteria have been made more strict. This implies that patients with a physical impairment may not receive treatment in comparison to previous years which can have a negative impact on their quality of life. Compliance with guidelines at our centre in the case for both liposuction and mastopexy has not been $100 \%$ as $16 \%$ of both these procedures were approved. Non-compliance is attributable to clinical decisions about the difficulties presented by the individual person and how these fit with the overall aim of the guidance in addressing disfigurement, functional problems and, to a lesser extent, psychosocial distress. A wide variation in policies exists across trusts within the UK when compared with our centre. 
This has meant that a 'postcode lottery' may dictate whether a patient is eligible for treatment. Differences in commissioning of funds are likely to be a key factor, and perhaps, policies can be made homogeneous if a more equal distribution of budget is allocated. It would be worthwhile comparing outcomes in this study to those at other hospital trusts. The authors would therefore like to encourage similar work to be conducted at other centres to enable a national comparison of results. This will help to identify whether the regional trend observed under the influence of the North Central London Hospitals NHS Trust care commissioning group is reflected across the UK. Wider sharing of such data could help raise awareness of increased difficulty posed to patients in accessing treatment. This could facilitate removal of discrepancies and develop more centralised ways in which patients could obtain the treatment they need.

Contributors All authors involved in this study have played a significant role and have abided to the ICMJE guidelines. They have all had (1) substantial contributions to conception and design, acquisition of data or analysis and interpretation of data; (2) drafting the article or revising it critically for important intellectual content; and (3) final approval of the version to be published. SR: manuscript write up, data collection, analysis and final approval. BL: manuscript write up, data collection, analysis and final approval. NH-H: manuscript write up, design, revision and final approval. EH: manuscript write up, data collection, revision and final approval. $A B$ : data collection, analysis, revision and final approval. NB: design, analysis, revision and final approval. SH: design, revision, analysis and final approval. AM: design, analysis, revision and final approval.

Competing interests None declared.

Patient consent Detail has been removed from this case description/these case descriptions to ensure anonymity. The editors and reviewers have seen the detailed information available and are satisfied that the information backs up the case the authors are making.

Provenance and peer review Not commissioned; externally peer reviewed.

Data sharing statement The authors grant access for the data in this article to be shared through open access.

Open Access This is an Open Access article distributed in accordance with the Creative Commons Attribution Non Commercial (CC BY-NC 4.0) license, which permits others to distribute, remix, adapt, build upon this work non-commercially, and license their derivative works on different terms, provided the original work is properly cited and the use is non-commercial. See: http://creativecommons.org/ licenses/by-nc/4.0/

(C) Article author(s) (or their employer(s) unless otherwise stated in the text of the article) 2017. All rights reserved. No commercial use is permitted unless otherwise expressly granted.

\section{REFERENCES}

1. British Association of Aesthetic Plastic Surgeons www.baaps.org.uk

2. Ercolani M, Baldaro B, Rossi N, et al. Short-term outcome of rhinoplasty for medical or cosmetic indication. $J$ Psychosom Res 1999;47:277-81.

3. Wilkins EG, Cederna PS, Lowery JC, et al. Prospective analysis of psychosocial outcomes in breast reconstruction: one-year postoperative results from the Michigan Breast Reconstruction Outcome Study. Plast Reconstr Surg 2000;106:1014-25.

4. Breuning EE, Oikonomou D, Singh P, et al. Cosmetic surgery in the NHS: applying local and national guidelines. $J$ Plast Reconstr Aesthet Surg 2010;63:1437-42.

5. Soldin M, Mughal M Al-Hadithy $\mathrm{N}$ et al. National commissioning guidelines: body contouring surgery after massive weight loss. $J$ Plast Reconstr Aesthet Surg 2014;67:e1081.

6. Cook SA, Rosser R, Meah S, et al. Clinical decision guidelines for NHS cosmetic surgery: analysis of current limitations and recommendations for future development. Br J Plast Surg 2003;56(429-36

7. www.rcseng.ac.uk/healthcare-bodies/docs/breast-reductioncommissioning-guide.

8. Clarke A, Lester KJ, Withey SJ, et al. A funding model for a psychological service to plastic and reconstructive surgery in UK practice. Br J Plast Surg 2005;58:708-13.

9. Coriddi MR, Koltz PF, Chen R, et al. Changes in quality of life and functional status following abdominal contouring in the massive weight loss population. Plast Reconstr Surg2011;128:520-6.

10. Bolton MA, Pruzinsky T, Cash TF, et al. Measuring outcomes in plastic surgery: body image and quality of life in abdominoplasty patients. Plast Reconstr Surg 2003;112:619-25.

11. Foreman KB, Dibble LE, Droge J, et al. The impact of breast reduction surgery on low-back compressive forces and function in individuals with macromastia. Plast Reconstr Surg 2009;124:1393-9.

12. Klassen $A$, Fitzpatrick $R$, Jenkinson $C$, et al. Should breast reduction surgery be rationed? A comparison of the health status of patients before and after treatment: postal questionnaire survey. BMJ 1996;313:454-7.

13. Wraight WM, Tay SK, Nduka C, et al. Bilateral breast reduction surgery in England: a postcode lottery. J Plast Reconstr Aesthet Surg 2007;60:1039-44.

14. Henderson J. The plastic surgery postcode lottery in England. Int $J$ Surg 2009:7:550-8.

15. Al-Hadithy N, Mennie J, Magos T, et al. Desire for post bariatric body contouring in South East Scotland. J Plast Reconstr Aesthet Surg 2013;66:87-94

16. Russell J, Swinglehurst D, Greenhalgh T. 'Cosmetic boob jobs' or evidence-based breast surgery: an interpretive policy analysis of the rationing of 'low value' treatments in the English National Health Service. BMC Health Serv Res 2014;14:14.11.

17. Local variations in healthcare spending. Kings fund report 2006 . www. kingsfund.org.uk/publications/briefings/local_variations.html.

18. Al-Zaidy S: national Versus Local Equity. how much variation is acceptable to doctors? London: BMA Health Policy and Research Unit, 2013. 